\title{
Simulated Relationships between Regional Temperatures and Large-Scale Circulation: 125 kyr BP (Eemian) and the Preindustrial Period
}

\author{
Nikolaus Groll, Martin Widmann, and Julie M. Jones \\ Institute for Coastal Research, GKSS Research Centre, Geesthacht, Germany \\ Frank Kaspar AND StePhan J. LORENZ \\ Model and Data Group, Max Planck Institute for Meteorology, Hamburg, Germany
}

(Manuscript received 21 August 2004, in final form 18 February 2005)

\begin{abstract}
To investigate relationships between large-scale circulation and regional-scale temperatures during the last (Eemian) interglacial, a simulation with a general circulation model (GCM) under orbital forcing conditions of $125 \mathrm{kyr} \mathrm{BP}$ is compared with a simulation forced with the Late Holocene preindustrial conditions. Consistent with previous GCM simulations for the Eemian, higher northern summer 2-m temperatures are found, which are directly related to the different insolation. Differences in the mean circulation are evident such as, for instance, stronger northern winter westerlies toward Europe, which are associated with warmer temperatures in central and northeastern Europe in the Eemian simulation, while the circulation variability, analyzed by means of a principal component analysis of the sea level pressure (SLP) field, is very similar in both periods.

As a consequence of the differences in the mean circulation the simulated Arctic Oscillation (AO) temperature signal in the northern winter, on interannual-to-multidecadal time scales, is weaker during the Eemian than today over large parts of the Northern Hemisphere. Correlations between the AO index and the central European temperature (CET) decrease by about 0.2 . The winter and spring SLP anomalies over the North Atlantic/European domain that are most strongly linearly linked to the CET cover a smaller area and are shifted westward over the North Atlantic during the Eemian. However, the strength of the connection between CET and these SLP anomalies is similar in both simulations.

The simulated differences in the AO temperature signal and in the SLP anomaly, which is linearly linked to the CET, suggest that during the Eemian the link between the large-scale circulation and temperaturesensitive proxy data from Europe may differ from present-day conditions and that this difference should be taken into account when inferring large-scale climate from temperature-sensitive proxy data.
\end{abstract}

\section{Introduction}

The quantification of natural climate variability and the understanding of its causes are a prerequisite for assessing the influence of human activities on climate, as well as for making meaningful long-term climate predictions. Investigating variability on long time scales requires estimates for the climate before the instrumental period. These can be obtained from climate proxy data and from numerical simulations. Intensively studied periods include the Holocene, the Last Glacial

Corresponding author address: Nikolaus Groll, Institute for Coastal Research, GKSS Research Centre, D21502 Geesthacht, Germany.

E-mail: groll@gkss.de
Maximum (e.g., Joussaume and Taylor 2000), and the last interglacial (e.g., Kukla et al. 2002; van Kolfschoten et al. 2003; Kubatzki et al. 2000).

In this paper we analyze aspects of the climate during the last interglacial, the Eemian, which is thought to have been as warm as today's climate and which lasted approximately from 126 to $110 \mathrm{kyr}$ BP (Shackleton et al. 2003). We are motivated by a large amount of terrestrial proxy data that have been investigated for the Eemian compared to earlier interglacials. These proxy data have been used to reconstruct local or regional climatic and environmental conditions (e.g., Cheddadi et al. 1998; Kühl and Litt 2003), with some uncertainties due to analytical problems and nonclimate influences on the proxy data. When considered together, these regional reconstructions lead to an approximate de- 
scription of large-scale climate, although merging the information from individual records into a large-scale picture is complicated by dating uncertainties, which cause large uncertainties for estimating both the duration of (Shackleton et al. 2003) and the climate variability within (Tzedakis et al. 2003) the Eemain.

Regional atmospheric temperatures on centennial and longer time scales can be influenced by many factors, including insolation changes due to variations in the earth's orbit or in solar irradiance, changed radiative balance due to altered composition of the atmosphere or the land surface, and forced or random changes in ocean circulation and, in turn, in sea surface temperatures (SSTs). The regional temperatures cannot only be directly linked to the forcing factors through changes in the regional radiative balance, but also through changes in the mean atmospheric circulation in response to the forcings. Feedbacks between the atmosphere, the ocean, the cryosphere, and the biosphere can further modify the temperature response to varying atmospheric forcings.

On interannual to multidecadal time scales there is considerable variability of the atmospheric circulation, which additionally influences regional temperatures. A large fraction of this variability is random and internally generated within the atmosphere or within the coupled atmosphere-ocean system, but atmospheric circulation variability can also be caused by fast varying forcing factors such as changes in solar irradiance, atmospheric concentrations of volcanic aerosols, or SST fluctuations due to internal ocean dynamics. In contrast to longerterm circulation changes, which are usually described as a changed mean state, the shorter-term changes are commonly understood as anomalies from a longer term, for instance centennial, mean circulation. These anomalies are often expressed in a compact way in terms of amplitudes of dominant variability modes such as the Arctic Oscillation (AO) or North Atlantic Oscillation (NAO). The influence of interannual to multidecadal circulation variability on regional temperatures has been intensively studied for the instrumental period (e.g., Hurrell 1995; Wallace et al. 1995). First model-based studies for earlier periods in the Late Holocene have recently been undertaken (e.g., Zorita et al. 2004). As far as we know our study addresses this issue for the first time for the last interglacial.

Describing the link between circulation and temperature is needed for understanding the circulation signal in temperature-sensitive proxy data. For the Late Holocene, proxy data have been directly linked to circulation variability by means of regression-based upscaling models. These models have been applied to recon- struct circulation anomalies from temperature- and precipitation-sensitive proxy data (e.g., Cook et al. 2002; D'Arrigo et al. 2003; Jones and Widmann 2003). The same approach has also been used to reconstruct large-scale temperature fields from proxy data and long instrumental records (e.g., Mann et al. 1999; Briffa et al. 2001; Esper et al. 2002; Luterbacher et al. 2004). In all of these cases the statistical models were fitted during the overlap period of the proxy records and the instrumental meteorological measurements, and stability of the statistical relationship throughout the reconstruction period has been assumed. This approach is not directly applicable to earlier periods, such as the Eemian, for several reasons. First, the dating uncertainties do not allow using proxy records from multiple sites as multivariate predictors. Second, most Eemian proxies with high temporal resolution, in particular terrestrial records, do not cover both the Eemian and the preindustrial period and thus one cannot fit and apply statistical models directly. Finally, the Eemian climate may have differed considerably from conditions during the instrumental period, and therefore one cannot expect the upscaling relationships to be similar to those derived under modern conditions.

The first problem cannot be overcome unless at least the relative dating between the records becomes more accurate, for instance, by using marker events. Thus, for the Eemian one is so far restricted to applying upscaling relationships to individual proxy records. The second problem may be resolved soon. Until recently the maximum temporal resolution of published Eemian terrestrial continuous proxy data was around $100 \mathrm{yr}$ (e.g., Tzedakis et al. 2003), but now records with higher temporal resolution are becoming available (e.g., Seelos 2004; Seelos and Sirocko 2004). Yet, even if the first and second issues were resolved, one would still be confronted with the third problem. This cannot be easily addressed based on proxy data only because there are no proxy data that are directly sensitive to circulation; therefore, one cannot investigate the empirical relationship between large-scale circulation and regional temperature.

In this paper we tackle the third issue by using a simulated climate as a surrogate for the real Eemian climate and by analyzing the relationship between regional temperatures and the large-scale circulation. We use a quasi-equilibrium simulation with the ECHAM4 Hamburg Ocean Primitive Equation (HOPE-G) model (ECHO-G; Legutke and Voss 1999) coupled atmosphere-ocean general circulation model (AOGCM) with orbital forcing for $125 \mathrm{kyr}$ BP (Kaspar et al. 2004). This simulation should represent a period when the de- 
TABLE 1. Experimental setup for PI: simulation with preindustrial GHG concentrations and current parameters of the earth's orbit; EEM: simulation with GHG concentrations and earth's orbital parameters for $125 \mathrm{kyr}$ BP vernal equinox (VE).

\begin{tabular}{lcccccccc}
\hline \hline & & & & & & & \multicolumn{2}{c}{ Duration of } \\
\cline { 3 - 8 } \multicolumn{1}{c}{ Expt } & $\begin{array}{c}\mathrm{CO}_{2} \\
(\mathrm{ppm})\end{array}$ & $\begin{array}{c}\mathrm{CH}_{4} \\
(\mathrm{ppb})\end{array}$ & $\begin{array}{c}\mathrm{N}_{2} \mathrm{O} \\
(\mathrm{ppb})\end{array}$ & $\begin{array}{c}\text { Eccentricity } \\
(\%)\end{array}$ & $\begin{array}{c}\text { Obliquity } \\
\text { axis tilt }\left({ }^{\circ}\right)\end{array}$ & $\begin{array}{c}\text { Perihelion } \\
\left({ }^{\circ} \text { from the VE) }\right.\end{array}$ & $\begin{array}{c}\text { simulation } \\
(\mathrm{yr})\end{array}$ & $\begin{array}{c}\text { model } \\
\text { spinup }(\mathrm{yr})\end{array}$ \\
\hline PI (1800 A.D.) & 280 & 700 & 265 & 1.67 & 23.44 & 282.7 & 1000 & 1300 \\
EEM (125 kyr BP) & 270 & 630 & 260 & 4.00 & 23.79 & 127.3 & 1000 & 1000 \\
\hline
\end{tabular}

glaciation after the previous glacial was finished and a relatively stable climate was reached. For comparison we apply the same analysis to a quasi-equilibrium simulation for preindustrial conditions around the year 1800 A.D. with the same model (Lorenz and Lohmann 2004).

GCM-based upscaling models, the so-called pseudoproxy approach, have been used already for the Holocene for aiding the interpretation of proxy-based climate reconstructions (e.g., Zorita and GonzálezRouco 2002; Rutherford et al. 2003; von Storch et al. 2004), but not yet for the Eemian. Some simulations for the Eemian have been undertaken with energy balance models (e.g., Crowley and Kim 1994) and models of intermediate complexity (e.g., Kubatzki et al. 2000; Crucifix and Loutre 2002), which do not represent the atmosphere in enough detail for pseudoproxy studies. Earlier simulations with atmosphere only GCMs (e.g., Royer et al. 1984; Prell and Kutzbach 1987; Kutzbach et al. 1991; de Noblet et al. 1996; Khodri et al. 2003; Vettoretti and Peltier 2004) and coupled AOGCMs (e.g., Montoya et al. 2000) focused on the mean climate of the atmosphere and the ocean. A transient simulation of the Eemian climate has been undertaken by Felis et al. (2004) using the same model as in our study, but with an acceleration technique for the orbital forcing (Lorenz and Lohmann 2004). The simulation used in our study provides 1000 years of simulated equilibrium climate for the early Eemian period (125 kyr BP) and is thus more suited for our study than the simulation of Felis et al. (2004), which provides only a few years with orbital forcing at $125 \mathrm{kyr}$ BP.

A brief description of the model and its setup is given in section 2. In section 3 mean circulation and temperature are discussed as well as the circulation variability. In section 4 the relationship between large-scale circulation and regional temperatures is analyzed and finally a summary and conclusions are presented in section 5 .

\section{Model description and experimental setups}

\section{a. The climate model}

The climate model used in the present study is the ECHO-G coupled AOGCM (Legutke and Voss 1999), which consists of the atmospheric model ECHAM4 (Roeckner et al. 1996) and the ocean model HOPE (Wolff et al. 1997) with a thermodynamic-dynamic sea ice model included (HOPE-G). In the analyzed simulations the ECHAM4 model has a spectral resolution of T30 (approximately $3.75^{\circ} \times 3.75^{\circ}$ ) with 19 vertical levels. The ocean model HOPE-G has a horizontal resolution of T42 (about $2.8^{\circ} \times 2.8^{\circ}$ ) with a meridional grid refinement in the tropical regions for the purpose of modeling ENSO variability and a vertical resolution of 20 levels. To avoid a climate drift a flux correction for heat and freshwater was applied; globally averaged over the ocean both fluxes are zero. The ECHO-G coupled AOGCM has been used in a number of recent climate variability studies (Baquero-Bernal et al. 2002; Marsland et al. 2003; Zorita et al. 2003; Rodgers et al. 2004; von Storch et al. 2004; Zorita et al. 2004).

\section{b. Experimental setups}

Two quasi-equilibrium simulations with fixed external forcing are analyzed: one for present-day insolation with preindustrial (around 1800 A.D.) greenhouse gas (GHG) concentrations (hereafter PI) (Lorenz and Lohmann 2004) and one with Eemian forcing conditions of 125 ky BP (hereafter EEM) (Kaspar et al. 2004). In the latter, insolation is calculated according to Berger (1978). GHG concentrations are taken from the Vostok ice core $\left(\mathrm{CO}_{2}\right.$ and $\mathrm{CH}_{4}$ : Petit et al. 1999; $\mathrm{N}_{2} \mathrm{O}$ : Sowers 2001). The changes in external forcing and boundary conditions are shown in Table 1. Both model simulations are started with the same initial state from a 1000yr quasi-equilibrium run with present-day greenhouse gases of the same model. After a model spinup of 1300 years (1000 years) in PI (EEM), a 1000-yr-long simulation period in both runs is analyzed. Both simulations show a global temperature trend of $-0.039 \mathrm{~K}$ century $^{-1}$ in PI and $-0.015 \mathrm{~K}$ century $^{-1}$ in EEM. In this study we primarily focus on the Northern Hemisphere where the temperature decrease is lower than the global trend. To compensate for this decrease we detrended the model output at all grid cells prior to analysis. Vegetation is fixed to its modern state in both runs. Note that therefore the feedback of a changed vegetation on the climate system (e.g., Doherty et al. 2000; Crucifix et al. 


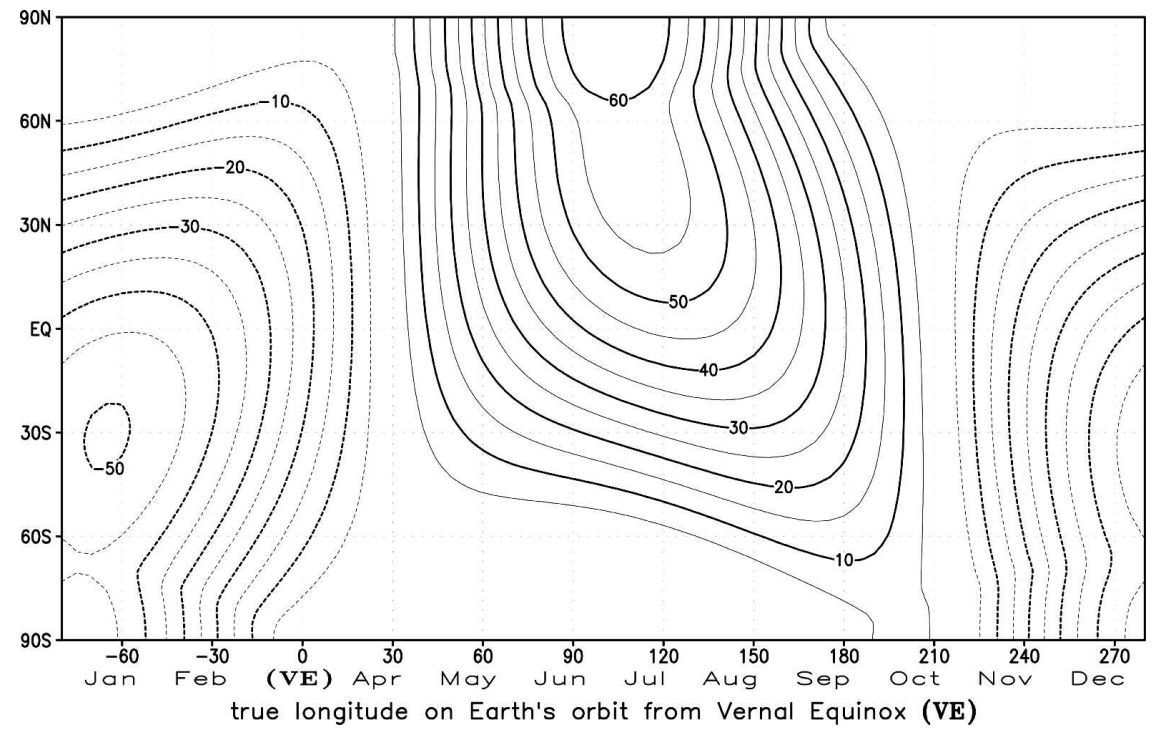

FIG. 1. Zonally averaged insolation anomalies $125000 \mathrm{yr}$ before present (125 kyr BP) as a function of true longitude on the earth's orbit from vernal equinox $\left(\mathrm{W} \mathrm{m}^{-2}\right)$ according to Berger (1978).

2002) is not included in our simulations. However, short test simulations with the same orbital forcing with a changed vegetation showed only minor effects on the large-scale climate in our model.

The EEM GHG concentrations are slightly lower than in PI, but the differences are small and it can be expected that they have only a minor influence on the differences between the two model runs and that the differences between the model runs are mainly caused by changes in the orbital parameters. Eccentricity is higher in the Eemian, but the effect on the global annual average of incoming solar radiation at the top of the atmosphere is only about $0.1 \%$. Obliquity is slightly greater at $125 \mathrm{kyr} \mathrm{BP}$ and with a fixed vernal equinox at 21 March, the perihelion occurs in July at $125 \mathrm{kyr}$ BP instead of in January as in the preindustrial period. The combined effect of changes in obliquity and in the timing of the perihelion leads to a higher (lower) global average insolation in northern (southern) Eemian summer of about $12 \%(11 \%)$ (Fig. 1) and to a larger (smaller) seasonality in incoming radiation in the Northern (Southern) Hemisphere.

Insolation is prescribed in the model with respect to the true longitude (angle on the orbit relative to the vernal equinox) on the changed earth orbit. Due to Kepler's law the time that the earth takes on the orbit per true longitude is different in the two simulated periods. As a consequence, a given date corresponds to a different true longitude on the orbit. This leads to different dates of the solstices and the fall equinox (vernal equinox is fixed) and to a reduction or extension of seasons (defined as sections on the orbit), for instance to a shorter northern summer and a longer northern winter, as shown in detail in Joussaume and Braconnot (1997).

In this study only monthly mean fields are analyzed, which are calculated by a standard postprocessing routine, based on a 360-day calendar year with 30 days month ${ }^{-1}$. Thus, we compare the climate averaged over slightly different sections of the earth's orbit. The effect of this on our results has been estimated by calculating all results for the Eemian simulation with respect to shorter northern summers (June and July) and longer northern winters (November to February) and comparison with the results for the preindustrial simulation with the standard definition of seasons. The differences caused by the different seasonal definitions are significantly smaller than those between the different simulations. Thus, here only results based on the standard season definition are discussed.

\section{Large-scale climate}

As a basis for understanding the changes in the relationship between large-scale circulation and regional temperature the differences in the mean climate and the circulation variability in the Eemian (125 kyr BP) and preindustrial simulations are discussed in this section.

\section{a. Long-term seasonal means}

A study by Min et al. (2004) with the same model as used in our study but with present-day GHG concen- 

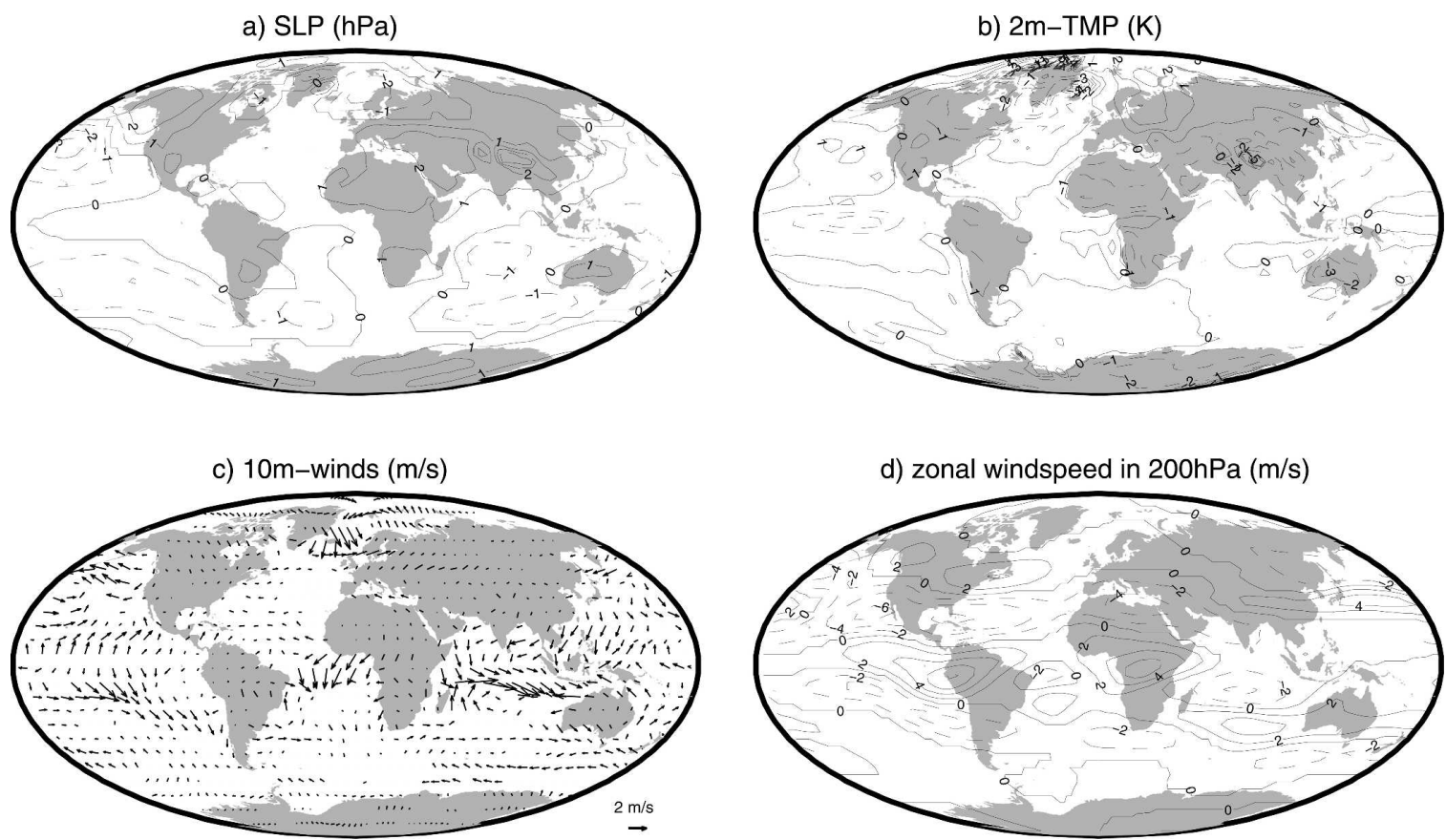

FIG. 2. Mean simulated difference (EEM minus PI) for DJF: (a) sea level pressure (hPa), (b) 2-m temperature (K), (c) $10-\mathrm{m}$ wind $\left(\mathrm{m} \mathrm{s}^{-1}\right)$, and (d) zonal wind speed at $200 \mathrm{hPa}\left(\mathrm{m} \mathrm{s}^{-1}\right)$. Solid (dashed) lines are positive (negative) anomalies.

trations shows that ECHO-G is capable of simulating the present-day mean climate well. The overall structure of long-term seasonal means of sea level pressure (SLP), 2-m temperature, 10-m wind field, and the zonal wind at $200 \mathrm{hPa}$ in EEM and PI are plausible. A detailed comparison of the simulated preindustrial and present-day climate with observations is beyond the scope of this paper. We only discuss differences between PI and EEM, and thus potential model biases can be expected to be compensated for to a large extent. A short comparison of the simulated and the climate estimated from proxy data is given at the end of this section.

A comparison of the boreal winter [DecemberFebruary (DJF)] sea level pressure field in the two simulations (Fig. 2a) shows lower SLP in EEM than in PI over the ocean basins and higher SLP over most parts of the land surface with the exception of northern and eastern Europe. Due to the lower insolation during DJF in the early Eemian compared to the preindustrial period, temperature is nearly everywhere lower in EEM compared to PI (Fig. 2b). An exception to this is the temperature in northern and eastern Europe, which is higher in EEM than in PI, with a maximum difference of $3 \mathrm{~K}$ over the Barents Sea. The difference in the 10-m wind field (Fig. 2c) shows weaker westerlies in the North Pacific as well as in the Southern Oceans, also trade winds in the Pacific Ocean are weaker. Stronger westerlies in northern Europe in EEM are evident, consistent with the lower pressure in that area amplifying the pressure gradient. These wind changes can partly explain the higher temperatures in northern Europe (Fig. 2b). Another contribution for the positive temperature anomalies comes from a lower sea ice extent (Kaspar et al. 2004) in this region (not shown). Changes in the ocean circulation (i.e., North Atlantic Deep Water formation), which could also contribute to the temperature anomaly in the Barents Sea, are small. A northward (southward) shift of the Atlantic (Pacific) jet (Fig. 2d) and a strengthening of the equatorial jet over South America and Africa can be seen, indicating that circulation changes do not only occur near the surface.

In northern summer [June-August (JJA)] the SLP (Fig. 3a) in the Eemian simulation is lower over the continents except over Australasia and Antarctica and higher over the North Pacific and over large parts of the Southern Oceans. Also an eastward shift of the Atlantic high and the southern Indian Ocean low pressure in EEM compared to PI can be found. An overall temperature increase (Fig. 3b) due to higher insolation in the early Eemian in the northern summer months can be seen, in particular over the Northern Hemisphere continents, up to $4 \mathrm{~K}$ in Siberia and Central Asia. Only in the monsoon regions of India and Africa is there a slight decrease, probably due to enhanced moisture transport from sea to land. This is consistent with stron- 

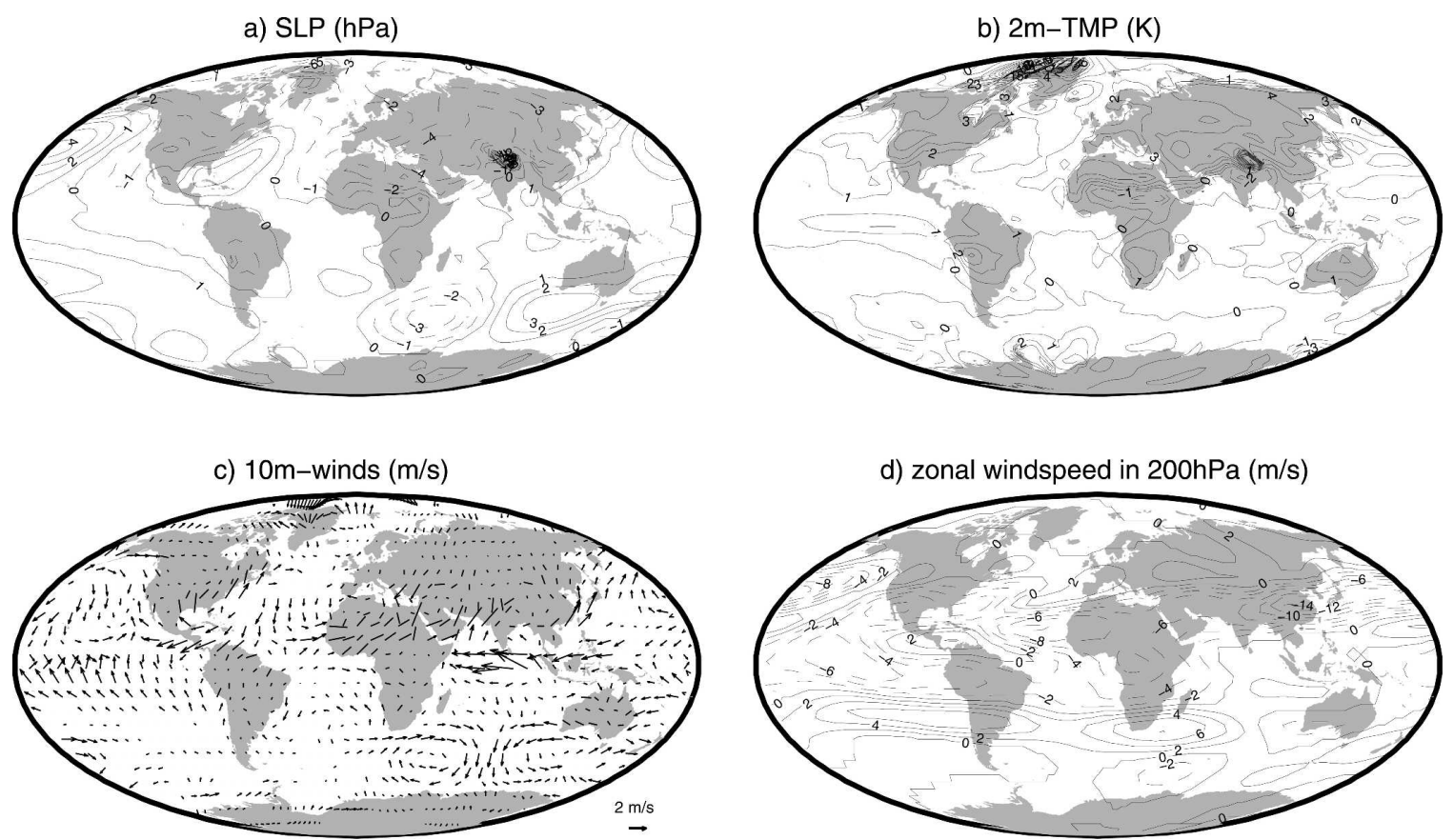

FIG. 3. As as Fig. 2 but for JJA.

ger southwest monsoon winds (Fig. 3c) toward India and western Africa in EEM. A strengthening of the Southern Hemisphere and equatorial jets (Fig. 3d) is evident. Wind speeds at the 200-hPa level over the Northern Hemisphere are reduced in EEM.

The simulated temperature differences between EEM and PI are consistent with temperature fields reconstructed from proxy data (e.g., Frenzel et al. 1992; Kaspar et al. 2004). The simulated stronger African monsoon in EEM is consistent with a proxy-based study by Rohling et al. (2002). This agreement between simulated and reconstructed fields show that the model is capable of reproducing a realistic mean climate at 125 kyr BP.

A study by Montoya et al. (2000) of the same period of the last interglacial with an earlier version (ECHAM1) of the atmospheric model ECHAM4 and the large-scale geostrophic (LSG) ocean model instead of HOPE-G shows agreement in the overall structure of simulated temperature, wind, and sea level pressure fields in summer. Only on the subcontinental scale are some differences evident, due to the lower spatial resolution of the model used by Montoya et al. (2000). In the winter season there are some differences. In particular, in the Northern Hemisphere the temperature anomalies in the North Atlantic/European domain are shifted westward and inverted. SLP anomalies over the North Pacific/North American domain are also inverted. However, a comparison between the two stud- ies is problematic because in Montoya et al. (2000) simulated differences between the early Eemian and the present-day climate are discussed, whereas in our study the last interglacial is compared with a control run with preindustrial GHG concentrations.

\section{b. Variability of the Northern Hemispheric circulation}

A standard approach to obtain the dominant patterns of variability in a dataset is to derive empirical orthogonal functions (EOFs). The first extratropical SLP EOF $\left(20^{\circ}-90^{\circ} \mathrm{N}\right)$ is physically interpretable, and is known as the AO or Northern Hemisphere Annular Mode (Thompson and Wallace 2000). The time-dependent amplitude of the AO, which is given by the first principal component (PC), is known as the Arctic Oscillation index (AOI). In the top (bottom) panels in Fig. 4 the first SLP EOFs for EEM (PI) for the four standard seasons are shown. Both experiments show very similar patterns, particularly in the winter season, namely a pronounced dipole over the North Atlantic corresponding to the NAO and a weaker dipole over the North Pacific. The EOF loadings, which here are scaled to be the pressure changes associated with a positive one standard deviation change in the AOI, are slightly larger in EEM in winter and spring in the Atlantic sector and smaller in winter in the Pacific. In the other seasons there are only small difference between EEM 

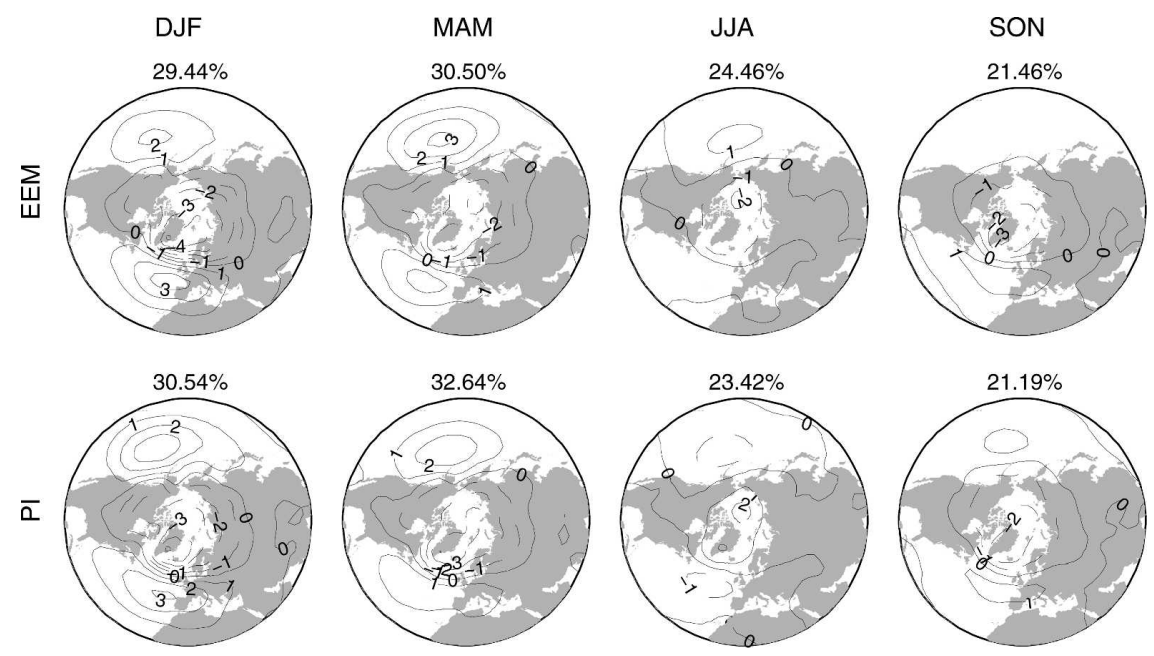

FIG. 4. First EOF for seasonal SLP: $1000 \mathrm{yr}$ (top) EEM and (bottom) PI. Percentages of explained variance are shown at the top of each panel.

and PI. The fraction of variance explained by EOF1 (Fig. 4) is very similar in both runs in all seasons. The second and third EOFs (not shown) do not differ much between the two runs.

The complexity of the circulation is reflected in the eigenvalue spectrum of the covariance matrix, or equivalently in the fraction of variance explained by the EOFs. A simple circulation is associated with a faster drop in explained variances or eigenvalues than a complex circulation. A suitable measure for the complexity is the number of independent degrees of freedom (DOFs), which can be calculated from the eigenvalue spectrum (Bretherton et al. 1999). In the EEM and PI simulations the explained variances and the DOFs based on monthly SLP are very similar in all seasons (e.g., in winter $\mathrm{DOF}=8.0$ in $\mathrm{EEM}$ and $\mathrm{DOF}=7.3$ in PI). EOF analysis of the 500-hPa geopotential height shows similar results (not shown). The stability of the EOFs in the 1000-yr-long equilibrium simulations are tested by splitting the simulations into ten 100 -yr-long time slices (not shown). The difference between the EOFs for the subperiods are small compared to the difference between EEM and PI.

The EOF pattern and its corresponding indices are calculated separately for each season and simulation and thus describe anomalies to different means. To study the combined effect of changes in the SLP mean and EOF1 we calculated SLP composite maps for AOI situations with plus or minus two standard deviations (Fig. 5). The distribution of the AOI is nearly Gaussian in both runs, so for every composite plot a set of about 25 seasons out of 1000 in the entire simulation is used.

\section{1) North Atlantic/Europe}

In the positive DJF AO phase there is no large difference between the two simulations (Fig. 5, middle column), but in the negative phase (Fig. 5, right column) the zonal flow over Europe is stronger in EEM, which could lead to a stronger oceanic influence in the eastern parts of Europe. The positive spring AO state (not shown) is associated with weaker zonal flow over the Atlantic and toward Europe in EEM than in PI. For negative spring $\mathrm{AO}$ phases there is no large difference in the southern and central parts of Europe, but a higher SLP gradient between Greenland and the Norwegian Sea in EEM could establish a more temperate climate in northern Europe during negative phases. In summer and fall (not shown) there is no difference between the two runs in the SLP fields associated with positive and negative $\mathrm{AO}$ phases.

\section{2) North Pacific/North America}

In winter there is no difference in positive or negative AO phases between the two model runs in this region. In spring weaker zonal flow toward the Pacific coast occurs in both AO phases in EEM. In summer and fall a greater SLP gradient over North America is evident in both $\mathrm{AO}$ phases.

In summary, the composite maps indicate a stronger DJF SLP gradient over Europe in EEM in negative AO phases compared to PI, whereas in positive $\mathrm{AO}$ phases the SLP gradient over Europe is very similar in both simulations. This suggests that the difference in the characteristics of the flow over Europe between positive and negative AO phases is smaller in the early 

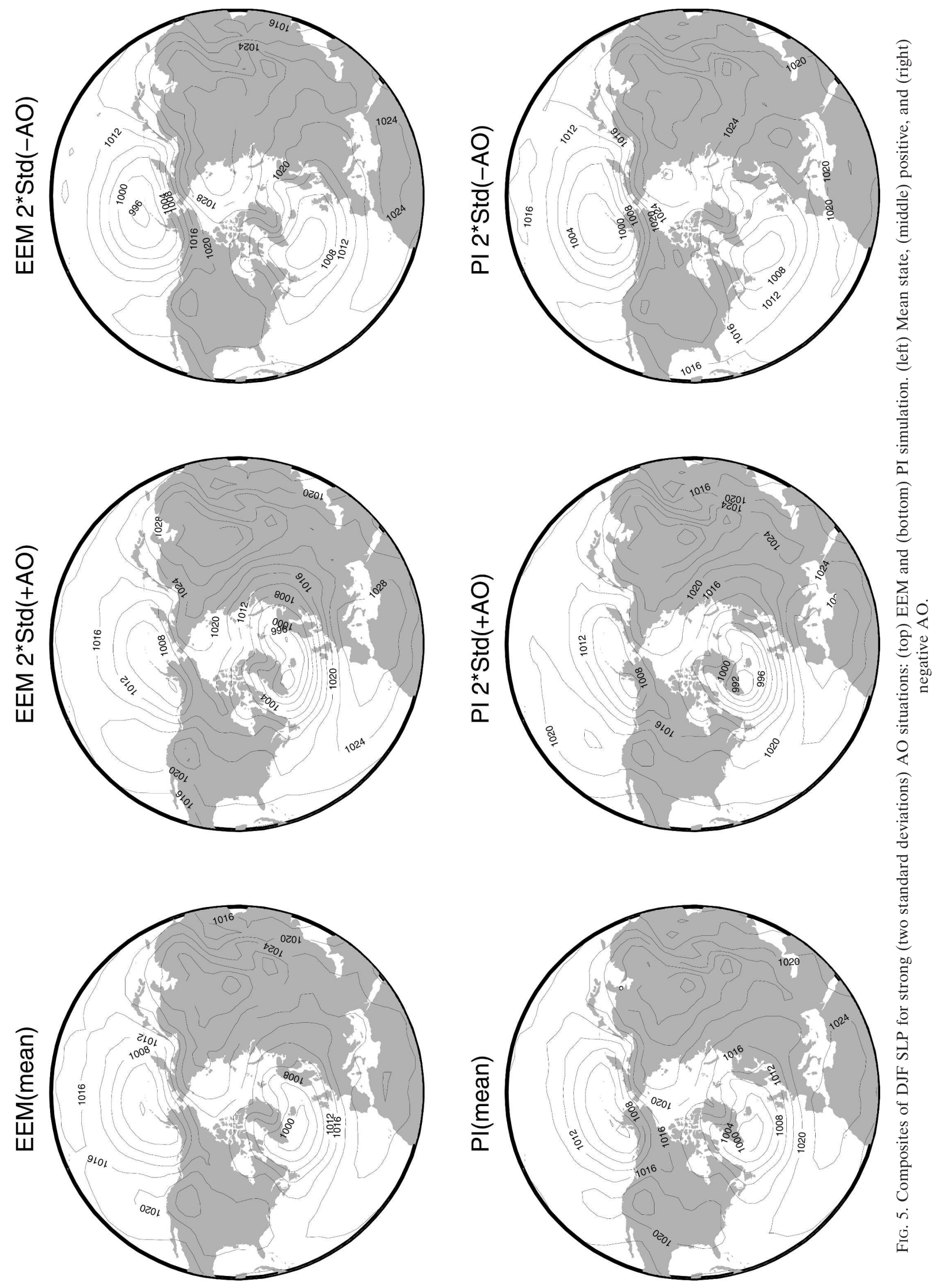


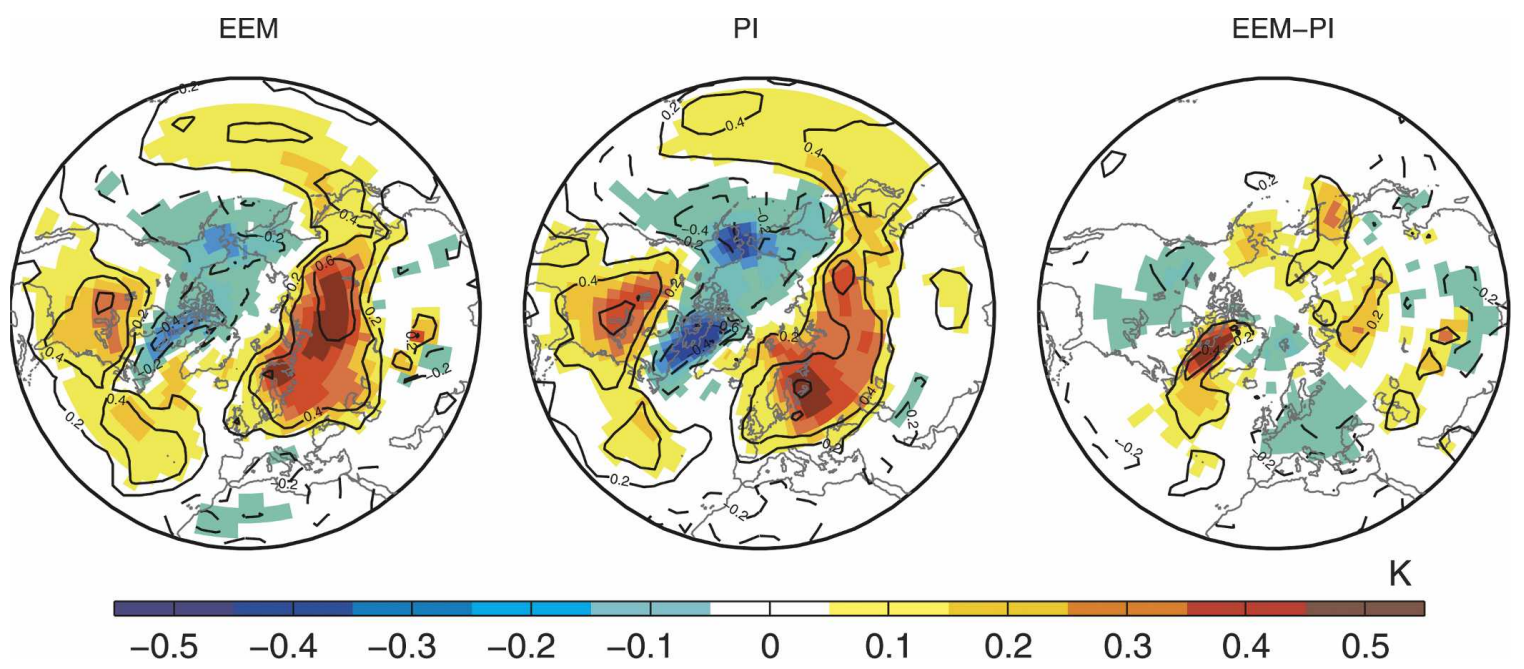

FIG. 6. Winter (DJF) AO temperature signal for (left) EEM, (middle) PI, and (right) difference between the simulations: regression coefficients in color, only values larger than $0.05 \mathrm{~K}$ shown. Correlation coefficients as contours: positive (negative) correlations shown as solid (dashed) lines, contour interval 0.2.

Eemian than in the preindustrial period and that this could lead to a weaker relationship between European temperature and the $\mathrm{AO}$ during the Eemian.

\section{Relationships between large-scale circulation and regional temperature}

In this section we investigate how circulation variability is linked to regional temperatures and thus, in turn, to temperature-sensitive proxy data. All correlations and differences discussed in this section are at least significant at the $1 \%$ level due to the long model simulation, but only correlations and differences that are large enough to be relevant for this study will be discussed.

\section{a. The AO temperature signal}

To assess whether temperature sensitive proxy data from the Northern Hemisphere may contain an AO signal on multidecadal time scales during the Eemian, we now investigate the temperature signal of the $\mathrm{AO}$ by calculating correlation and regression coefficients between the standardized AOI and the 2-m temperature of the two simulations. We use a 31-yr Hamming filter (Oppenheim and Schafer 1989) for analyzing the AO signal as this time scale is long enough to be resolved by continuous proxy data, but short enough for regional temperature to be strongly linked to circulation variability. As the AO temperature signal is often considered on interannual time scales, we also calculated the AO temperature signal with annual data from the simulations (not shown). The overall structure of the annual and multidecadal $\mathrm{AO}$ temperature signal is similar and the differences between the EEM and PI simulation on annual time scales are comparable to those on multidecadal time scales.

The regression (colored) and correlation (contour lines) coefficients for the winter season (DJF) are shown in Fig. 6. The preindustrial simulation (middle panel) reproduces the observed AO temperature signal (e.g., Thompson and Wallace 2000; Hurrell 1995) reasonably well (not shown). Positive regression coefficients over northern and eastern Europe and Siberia of up to $0.5 \mathrm{~K}$ per one standard deviation of the AOI, and a maximum correlation of 0.6 are evident, which reflects that a positive AOI is associated with stronger westerlies and as a consequence with positive temperature anomalies over Europe. Most parts of North America are also positively correlated $(\max 0.6)$ with regression coefficients of up to $0.4 \mathrm{~K}$, which also suggests that a positive AOI is associated with positive SST (2-m temperature) anomalies over the Sargasso Sea (southeast of the United States). Around the Bering Sea and west of Greenland the AOI is negatively correlated with up to -0.6 with the temperature anomaly (regression coefficient approximately $-0.6 \mathrm{~K}$ ). The negative temperature anomalies are associated with more storms and cold air advection from the Arctic regions in positive AOI situations.

In the EEM simulation the spatial distribution of the DJF AO temperature signal is very similar (Fig. 6, left panel), but with generally lower values for the regression and correlation coefficients. To get a more detailed view of the changes in the $\mathrm{AO}$ temperature signal in 
terms of strength and displacement of centers, the difference (EEM minus PI) was calculated (Fig. 6, right panel). Negative deviations of regression coefficients of $0.1 \mathrm{~K}$ over Europe and parts of North America, together with a weaker correlation (up to -0.2 ) over western and central Europe as well as in western Canada are evident. Positive differences can be found west of Greenland $(0.5 \mathrm{~K})$ that signify a weakened simulated Eemian AO signal in this region because in EEM the signal is less negative (Fig. 6, left panel). Also, in Alaska and in the Sea of Okhotsk positive deviations represent a weaker AO temperature signal. Only in parts of Siberia is the strength of the AO signal stronger, by up to $0.3 \mathrm{~K}$, and the correlation is higher by about 0.2 .

As most of the available terrestrial proxy data for the last interglacial are located in Europe, we now focus on the changes of the AO signal in Europe. The greatest differences can be found in central Europe, where regression coefficients drop by about $40 \%$ and the correlation drops proportionally from 0.4 in PI to 0.2 in EEM (Fig. 6). In western Europe there is a weak AO temperature signal in PI, which completely vanishes in EEM. Thus, in large parts of Europe the AO explains less of the multidecadal winter temperature variability in EEM than in PI. This simulated difference of the AO temperature signal between the two simulations is consistent with the results discussed in section $3 b$, where differences in the SLP gradient over Europe between positive and negative $\mathrm{AO}$ phases were found to be smaller in EEM than in PI.

A possible explanation for the different mean circulation and the weaker AO temperature signal in most parts of the Northern Hemisphere discussed in section $3 \mathrm{~b}$ could be that the boreal winter equator to pole difference in insolation and available energy is smaller 125 kyr BP. Changes in the meridional insolation gradient could lead to changes in the poleward extent of the Hadley cell, or to a reduction of the meridional energy transport by the eddy circulation, or to a combination of both. The smaller exchange of heat and air masses between the mid and high latitudes could lead to a more zonal flow in the midlatitudes. However this simple explanation does not explain the stronger $\mathrm{AO}$ signal over Siberia. More analysis is required to find an explanation for this disparity.

In summer (not shown) the AO temperature signal almost disappears in both simulations, which reflects the fact that during summer the hemispheric circulation does not play an important role for temperature variability. In the transition seasons (not shown) the AO temperature signal is weaker than in winter.

\section{b. Large-scale circulation and central European temperature}

The analysis of the AO temperature signal showed that the linear relationship between the AO and 2-m temperature in some parts of Europe is weaker in the EEM than in the PI simulation. However, this does not exclude that other SLP anomalies may exist whose amplitudes are strongly linked to European temperatures. One way of defining a SLP pattern that is linearly linked to central European temperature (CET) is through the regression coefficients of local SLP on CET. This definition is optimal in two ways: First, if one wants to estimate SLP anomalies from CET by means of linear regression, the estimate will be the product of the CET and this regression map. Note that an upscaling model for reconstructing circulation from European proxy data could be obtained by first estimating the CET from the proxy data and then multiplying it with the regression map. The second meaning of the regression map was pointed out by Widmann (2005), who showed that the regression coefficient are also proportional to the weights that would be given to the local SLP values for obtaining an estimate of the CET from the SLP field based on singular value decomposition. In the same paper it was also shown that this estimate can be expected to be very close to the result of a multiple linear regression (MLR) applied to the leading SLP PCs (PC-MLR) and that it may be somewhat less affected by overfitting problems. For brevity and because of the convenient dual interpretation of regression maps we restrict the discussion to the regression maps rather than also discussing the PC-MLR weights.

We regressed the SLP field over the North Atlantic and over Europe onto the CET, defined as the area mean of the 2-m temperature at eight highly correlated grid cells over western and central Europe $\left(50.1^{\circ}-\right.$ $\left.46.4^{\circ} \mathrm{N}, 3.75^{\circ}-15^{\circ} \mathrm{E}\right)$. Again a $31-\mathrm{yr}$ Hamming filter was used. As climate proxy data frequently represent monthly mean values (e.g., the warmest or coldest month, e.g., Aalbersberg and Litt 1998; Klotz et al. 2003), we analyzed regression maps based on monthly rather than on seasonal means.

For both simulations Fig. 7 shows the regression coefficients for filtered monthly means in $\mathrm{hPa} \mathrm{K}^{-1}$ in color and the correlations as contour lines. In January the maximum PI values are south of Italy, indicating that over this area a pressure increase of about $1.25 \mathrm{hPa}$ can be estimated from a CET increase of $1 \mathrm{~K}$ with a correlation of about 0.4 . The minima with values of around $-2 \mathrm{hPa} \mathrm{K}{ }^{-1}$ and correlations of about -0.4 reaches from the North Atlantic over Scandinavia into northern Russia. This pattern is synoptically plausible 

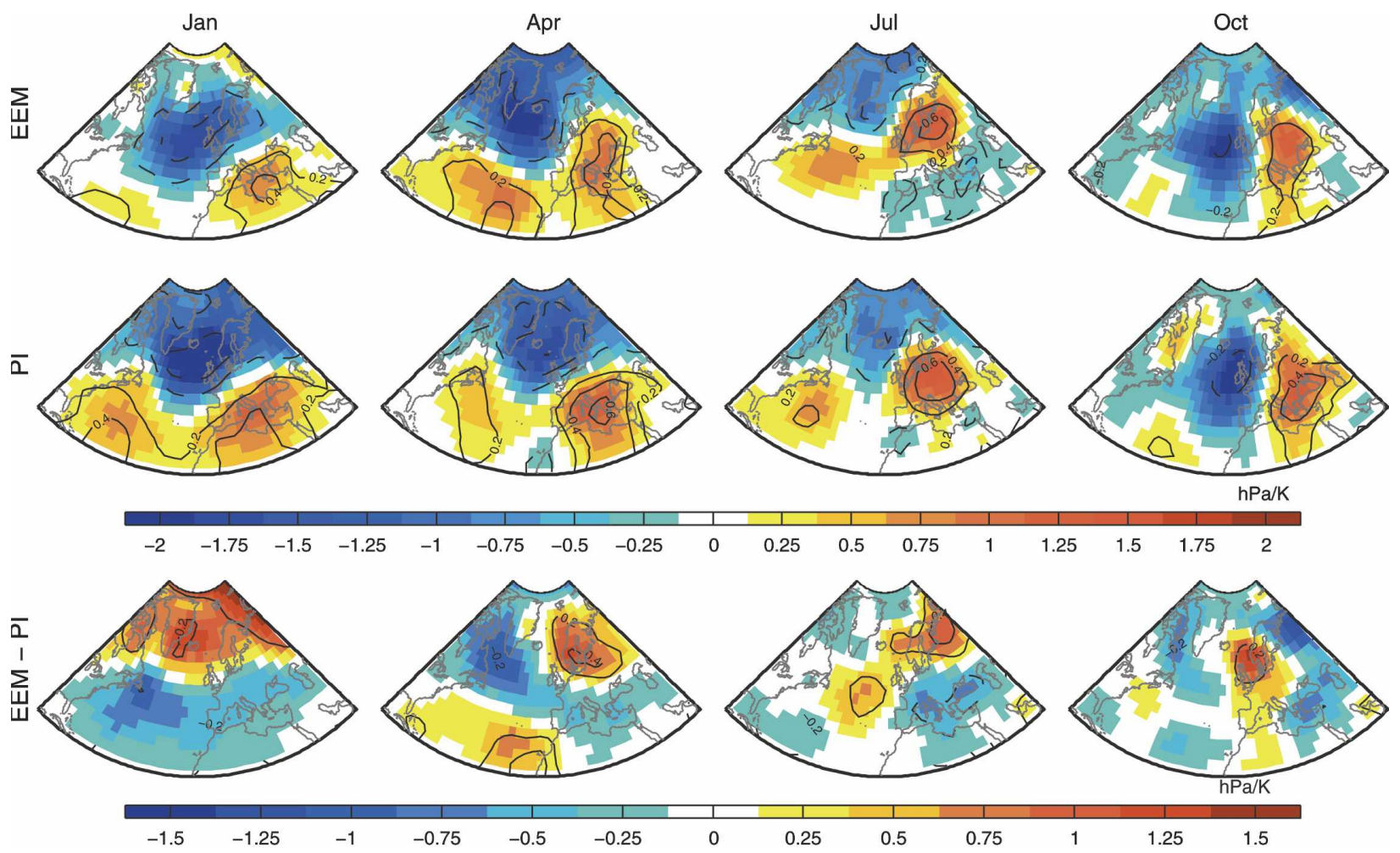

FIG. 7. Regression maps of monthly SLP on CET, filtered with a 31-yr Hamming filter for (top) EEM, (middle) PI, and (bottom) difference between the simulations: regression coefficients $\left(\mathrm{hPa} \mathrm{K}^{-1}\right)$ in color; only regressions stronger than $0.125 \mathrm{hPa} \mathrm{K}^{-1}$ shown. Correlation coefficients as contours: positive (negative) correlation shown as solid (dashed) lines; contour interval 0.2.

as with the sign shown it is associated with increased southwesterly flow toward central Europe and thus with the advection of mild air masses. With the opposite sign it is associated with a northeasterly flow anomaly and an increased influence of cold, continental air masses. The regression pattern in EEM in January also shows positive coefficients over the southern part of the domain and negative values over the North Atlantic, but there are some differences to PI. The region with positive coefficients is concentrated over the Mediterranean Sea and the values are reduced to about 0.75 $\mathrm{hPa} \mathrm{K}{ }^{-1}$. The area of negative coefficients is also smaller and the center is shifted slightly southwestward to the North Atlantic. The difference between the two regression patterns is shown in the bottom panel in Fig. 7. In the southern (northern) half of the domain the regression coefficients are more negative (positive) in the EEM compared to PI. This change suggests that in the EEM simulation the pressure anomalies over the northern North Atlantic have more influence on the CET than pressure anomalies over the southern North Atlantic and the Mediterranean Sea.

In April the spatial structure of the regression coefficients is the same as in January, but the two simulations differ slightly. The high positive values $\left(1.25 \mathrm{hPa} \mathrm{K}^{-1}\right)$ in the PI around the Mediterranean are slightly reduced $\left(1 \mathrm{hPa} \mathrm{K}^{-1}\right)$, and the positive area is extended east of the Baltic Sea. The positive values over the Atlantic are higher (from 0.5 to $1 \mathrm{hPa} \mathrm{K}^{-1}$ ) in EEM. The area with negative regression coefficients over Iceland is shifted to the center of the North Atlantic in EEM. In July the regression pattern is dominated by positive coefficients $\left(1.5 \mathrm{hPa} \mathrm{K}{ }^{-1}\right)$ over the European continent, which suggests that pressure anomalies over land induce summer CET anomalies (e.g., summer high pressure). This indicates that the continental summer climate and regional effects dominate the link between SLP and CET. The difference between the two runs is small, the center slightly shifted to the north in EEM. In October the regression coefficients have a dipole form with positive values over the continent and negative values over the Atlantic. In EEM the pattern is slightly weaker and is shifted westward. October marks the transition between summer with dominating pressure over land and winter with pressure influence from the North Atlantic.

To obtain a measure for the strength of the linear coupling between the SLP field and the CET, the timedependent amplitude of the regression pattern, the socalled time expansion coefficient (TEC), was calculated 
and correlated with the CET. The TEC was derived by an orthogonal projection of area-weighted SLP data onto the regression map or, in other words, as the scalar product of the two fields. The correlations range between 0.4 to 0.7 in both model runs with higher values in winter and summer months and lower correlations in the transition months. The squared correlation has a twofold meaning. It is the fraction of variance of the TEC of the regression map that can be explained by linear regression from the CET. This interpretation is appropriate when the upscaling problem is considered. The correlation is also the fraction of temperature variance that can be explained by linear regression from the TEC. It can be expected to be similar to the fraction of temperature variance that can be explained by a PCMLR (Widmann 2005).

Thus, in both simulations the amplitude of the SLPCET regression pattern can be equally well estimated form the CET, but the differences in the regression maps show that in the EEM simulation a smaller and different area of the SLP field in winter and spring can be explained by a linear upscaling relationship from the CET. Note that the very similar correlations in both simulations are not in conflict with the lower correlation in EEM between the AOI and the CET found earlier. The January and April regression patterns strongly project positively on the AO-NAO pattern but are not identical to it. The difference EEM - PI of the regression maps in January resembles very closely the inverted AO-NAO pattern, consistent with the reduced AOI-CET correlation discussed in section 4 .

\section{Summary and conclusions}

Two quasi-equilibrium simulations with an AOGCM, forced with different incoming solar radiation and greenhouse gas concentrations, typical for the last interglacial (EEM) and the preindustrial (PI) period, respectively, were compared. Simulated mean fields of circulation and temperature show substantial differences between the two runs. In winter 2-m temperatures in northern and eastern Europe are higher in the EEM simulation, partly related to stronger westerly flow toward these areas. In summer an overall increase in Northern Hemisphere 2-m temperatures can be found due to increased insolation. EOF analysis shows only slight differences in SLP variability in the North Atlantic and North Pacific. Composite SLP maps of situations with a strong positive or negative AOI, which capture the combined effect of the differences in the mean and the AO pattern, show considerable differences between the two periods during negative $\mathrm{AO}$ phases, with larger SLP gradients and increased zonal flow over Europe in EEM compared to PI.
The stability of the AO temperature signal was investigated by means of regression and correlation maps between the 31-yr filtered seasonal AOI and the filtered 2-m temperature field. The signal is strongest in winter in both simulations, but in EEM it is significantly weaker over Europe, west of Greenland, and north of Japan, but stable or higher over Siberia than in PI. In particular in central Europe the winter AO temperature regression coefficients are reduced in EEM by up to $40 \%$ and the correlation drops by about 0.2 . These changes in the relationship between AOI and CET are consistent with the lower variation in the EEM simulation of the strength of the winter zonal flow over Europe between positive and negative AOI states. Thus, the simulations suggest that during early Eemian winters less of the multidecadal temperature variability over Europe can be explained by the AO, and it can be expected that less information on the multidecadal AOI mean can be derived from temperature-sensitive proxy data from Europe. Over Siberia the simulated AO temperature signal is strong in both simulations.

To find the circulation pattern that has the strongest linear link to the temperature over Europe we regressed the 31-yr filtered monthly SLP over the Atlantic and Europe on the filtered central European temperature $(\mathrm{CET})$. The resulting regression maps show that winter and spring CET variability is linearly related to the SLP contrast between the high and the midlatitudes in both simulations. In July the CET variability is dominated by SLP variations over the European continent, and in fall by the contrast of the pressure anomalies over Europe and the Atlantic. In winter the difference between the two simulations is a weaker link during the early Eemian between the CET and SLP over the southern North Atlantic, the Mediterranean, and eastern Europe. In spring similar differences occur over the Mediterranean and eastern Europe, but the southern North Atlantic is more strongly linked during the early Eemian. In July and October only small differences are found.

The correlations between the time expansion coefficients of the regression maps and the CETs show that, despite the differences in the regression maps, the link between the amplitudes of the regression maps and the CETs is equally strong in both periods with correlations up to about 0.7 in winter. This is not in conflict with the reduced AOI-CET correlation during Eemian winters, as the January preindustrial regression map strongly projects positively on the AO-NAO pattern and the difference EEM - PI of the regression maps in January resembles the inverted $\mathrm{AO}-\mathrm{NAO}$ pattern. In other words, the wintertime SLP pattern with the strongest linear connection to the CET is in the preindustrial 
period more similar to the AO-NAO pattern than during the early Eemian.

Our model-based results confirm other numerical simulations that suggest that insolation changes due to changes in the earth's orbit do not only directly change temperatures, but also significantly alter the mean circulation over some areas, including Europe (e.g., Montoya et al. 2000; Felis et al. 2004). In addition our study shows that multidecadal circulation variability is very similar during the early Eemian and the preindustrial period but that, presumably as a consequence of the different mean circulation, the relationship between circulation variability and regional temperatures differs substantially. These changes should be taken into account if circulation variability is estimated from temperature-sensitive proxy data for the Eemian.

Acknowledgments. We thank Norbert Kühl for his comments and the four anonymous reviewers for their valuable comments that helped us to improve the manuscript. Stephanie Legutke is acknowledged for her support with the ECHO-G model and Beate Gardeike for help with figure preparation. This work was funded within the (Climate change at the very end of a warm stage) EEM project and the (Global Holocene Spatial and Temporal variability) GHOST project by the Federal Ministry of Education and Research under the (Deutsches Klimaforschungsprogramm) DEKLIM program.

\section{REFERENCES}

Aalbersberg, G., and T. Litt, 1998: Multiproxy climate reconstructions for the Eemian and Early Weichselian. J. Quat. Sci., 13, 367-390.

Baquero-Bernal, A., M. Latif, and S. Legutke, 2002: On dipolelike variability of sea surface temperature in the tropical Indian Ocean. J. Climate, 15, 1358-1368.

Berger, A. L., 1978: Long-term variations of daily insolation and Quaternary climatic changes. J. Atmos. Sci., 35, 2362-2367.

Bretherton, C., M. Widmann, V. P. Dymnikov, J. M. Wallace, and I. Bladé, 1999: The effective number of spatial degrees of freedom of a time-varying field. J. Climate, 12, 1990-2009.

Briffa, K. R., T. J. Osborn, F. H. Schweingruber, I. C. Harris, P. D. Jones, S. G. Shiyatov, and E. A. Vaganov, 2001: Low frequency temperature variations from a northern tree-ring density network. J. Geophys. Res., 106, 2929-2941.

Cheddadi, R., K. Mamakowa, J. Guiot, J. L. de Beaulieu, M. Reille, V. Andrieu, W. Granoszewski, and O. Peyron, 1998: Was the climate of the Eemain stable? A quantitative climate reconstruction from seven European pollen records. Palaeogeogr., Palaeoclimatol., Palaeoecol., 143, 73-85.

Cook, E. R., R. D. D'Arrigo, and M. E. Mann, 2002: A wellverified, multiproxy reconstruction of the winter North Atlantic Oscillation index since A.D. 1400. J. Climate, 15, 17541764.
Crowley, T., and K. Y. Kim, 1994: Milankovitch forcing of last interglacial sea level. Science, 265, 1566-1568.

Crucifix, M., and M. F. Loutre, 2002: Transient simulation over the last interglacial period (126-115 kyr BP): Feedback and forcing analysis. Climate Dyn., 19, 417-433.

$\longrightarrow,-$, P. Tulkens, T. Fichefet, and A. Berger, 2002: Climate evolution during the Holocene: A study with a Earth system model of intermediate complexity. Climate Dyn., 19, 43-60.

D'Arrigo, R. D., E. R. Cook, M. E. Mann, and J. C. Jacoby, 2003: Tree-ring reconstructions of temperature and sea-level pressure variability associated with the warm-season Arctic Oscillation since AD1650. Geophys. Res. Lett., 30, 1549, doi:10.1029/2003GL017250.

de Noblet, N., P. Braconnot, S. Joussaume, and V. Masson, 1996: Sensitivity of simulated Asian and African summer monsoons to orbitally induced variations in insolation 126,115 and 6kBP. Climate Dyn., 12, 589-603.

Doherty, R., J. Kutzbach, J. Foley, and D. Pollard, 2000: Fully coupled climate/dynamical vegetation model simulations over Northern Africa during the mid-Holocene. Climate Dyn., 16, 561-573.

Esper, J., E. R. Cook, and F. H. Schweingruber, 2002: Lowfrequency signals in long tree-ring chronologies for reconstructing past temperature variability. Science, 295, 22502254.

Felis, T., G. Lohmann, H. Kuhnert, S. J. Lorenz, D. Scholz, J. Pätzold, S. A. Al-Rousan, and S. M. Al-Moghrabi, 2004: Increased seasonality in Middle East temperatures during the last interglacial period. Nature, 429, 164-168.

Frenzel, B., M. Pécsi, and A. A. Velichko, 1992: Atlas of Paleoclimates and Paleoenvironments of the Northern Hemisphere, Late Pleistoncene-Holocene. Geographical Research Institute, Hungarian Academy of Science, 153 pp. [Available online at http://www.pangea.de/Projects/PKDB/PaleoAtlas. html.]

Hurrell, J. W., 1995: Decadal trends in the North Atlantic Oscillation: Regional temperature and precipitation. Science, 269, 676-679.

Jones, J. M., and M. Widmann, 2003: Instrument- and tree-ringbased estimates for the Antarctic Oscillation. J. Climate, 16, 3511-3524.

Joussaume, S., and P. Braconnot, 1997: Sensitivity of paleoclimate simulation results to season definitions. J. Geophys. Res., 102, 1943-1956.

_, and K. E. Taylor, 2000: The Paleoclimate Modeling Intercomparison Project. Paleoclimate Modeling Intercomparison Project (PMIP): Proceedings of the Third PMIP Workshop, WCRP-111, WMO/TD-1007, P. Braconnot, Ed., World Meteorological Organisation-World Climate Research Programme, 9-24.

Kaspar, F., N. Kühl, and U. Cubasch, 2004: Simulation of the Eemian interglacial with a coupled ocean-atmosphere model. Geophysical. Research Abstracts, EGU First General Assembly, Vol. 6, EGU04-A-04034, Nice, France, European Geosciences Union.

Khodri, M., G. Ramstein, and N. de NobletDucoudré, 2003: Sensitivity of the northern extratropics hydrological cycle to the changing insolation forcing at 126 and $115 \mathrm{ky}$ BP. Climate Dyn., 21, 273-287.

Klotz, S., J. Guiot, and V. Mosbrugger, 2003: Continental European Eemian and early Würmian climate evolution: Comparing signals using different quantitative reconstruction ap- 
proaches based on pollen. Global Planet. Change, 36, 277294

Kubatzki, C., M. Montoya, S. Rahmstorf, A. Ganopolski, and M. Claussen, 2000: Comparison of the last interglacial climate simulated by a coupled global model of intermediate complexity and an AOGCM. Climate Dyn., 16, 799-814.

Kühl, N., and T. Litt, 2003: Quantitative time series reconstruction of Eemian temperature at three European sites using pollen data. Veg. Hist. Archaeobot., 12, 205-214.

Kukla, G. J., and Coauthors, 2002: Last interglacial climates. Quat. Res., 58, 2-13.

Kutzbach, J. E., R. G. Gallimore, and P. Guetter, 1991: Sensitivity experiments on the effect of orbitally-caused insolation changes on the interglacial climate of northern latitudes. Quat. Int., 10-12, 223-229.

Legutke, S., and R. Voss, 1999: The Hamburg atmosphere-ocean coupled circulation model ECHO-G. Tech. Rep. 18, German Climate Computing Center (DKRZ), Hamburg, Germany, $62 \mathrm{pp}$.

Lorenz, S. J., and G. Lohmann, 2004: Acceleration technique for Milankovitch type forcing in a coupled atmosphere-ocean circulation model: Method and application for the Holocene. Climate Dyn., 23, doi:10.1007/s00382-004-0469-y.

Luterbacher, J., D. Dietrich, E. Xoplaki, M. Grosjean, and H. Wanner, 2004: European seasonal and annual temperature variability, trends, and extremes since 1500 . Science, 303, 1499-1503

Mann, M. E., R. S. Bradley, and M. K. Hughes, 1999: Global-scale temperature patterns and climate forcing over the past six centuries. Nature, 392, 779-787.

Marsland, S. J., M. Latif, and S. Legutke, 2003: Variability of the Antarctic Circumpolar Wave in a coupled ocean-atmosphere model. Ocean Dyn., 53, 323-331.

Min, S. K., S. Legutke, A. Hense, and W. T. Kwon, 2004: Climatology and internal variability in a 1000-year control simulation with the coupled climate model ECHO-G. Tech. Rep. 2, Gruppe Modelle \& Daten, Max Plank Institute for Meteorology, Hamburg, Germany, 67 pp.

Montoya, M., H. von Storch, and T. J. Crowley, 2000: Climate simulation for $125 \mathrm{kyr}$ BP with a coupled ocean-atmosphere general circulation model. J. Climate, 13, 1057-1071.

Oppenheim, A., and R. W. Schafer, 1989: Discrete-Time Signal Processing. Prentice-Hall, 879 pp.

Petit, J. R., and Coauthors, 1999: Climate and atmospheric history of the past 420000 years from the Vostok ice coreAntarctica. Nature, 399, 429-436.

Prell, W. L., and J. E. Kutzbach, 1987: Monsoon variability over the past 150000 years. J. Geophys. Res., 92, 8411-8425.

Rodgers, K., P. Friederichs, and M. Latif, 2004: Tropical Pacific decadal variability and its relation to decadal modulation of ENSO. J. Climate, 17, 3761-3774.

Roeckner, E., and Coauthors, 1996: The atmosphere general circulation model ECHAM-4: Model description and simulation of present-day climate. Tech. Rep. 218, Max Planck Institute for Meteorology, $90 \mathrm{pp}$.

Rohling, E. J., and Coauthors, 2002: African monsoon variability during the previous interglacial maximum. Earth Planet. Sci. Lett., 202, 61-75.

Royer, J. F., F. Deque, and P. Pestiaux, 1984: A sensitivity experiment to astronomical forcing with a spectral GCM: Simula- tion of the annual cycle at 125000 and 115 000BP. Milankovitch and Climate, A. Berger, Ed., NATO ASI Series, Vol. C126, Reidel, 733-736.

Rutherford, S., M. E. Mann, T. L. Delworth, and R. J. Stouffer, 2003: Climate field reconstruction under stationary and nonstationary forcing. J. Climate, 16, 462-479.

Seelos, K., 2004: Entwicklung einer numerischen Partikelanalyse auf Basis digitaler Dünnschliffaufnahmen und Anwendung der Methode auf die ELSA-HL2-Kernsequenz 66-41 m. $\mathrm{Ph} . \mathrm{D}$. thesis, University of Mainz, Mainz, Germany, 173 pp.

_ , and F. Sirocko, 2004: RADIUS-Rapid Particle Analysis of Digital Images by Ultra-High Resolution Scanning of thin sections. Sedimentology, 53, doi:10.1111/j.1365-3091. 2005.00715.x.

Shackleton, N. J., M. F. Sánchez Goñi, D. Pailler, and Y. Lancelot, 2003: Marine isotope substage 5e and the Eemain interglacial. Global Planet. Change, 36, 151-155.

Sowers, T., 2001: $\mathrm{N}_{2} \mathrm{O}$ record spanning the penultimate deglaciation from the Vostok ice core. J. Geophys. Res., 106, 31903 31914.

Thompson, D. W. J., and J. M. Wallace, 2000: Annular modes in extratropical circulation. Part I: Month-to-month variability. J. Climate, 13, 1000-1016.

Tzedakis, P., M. R. Frogley, and T. H. E. Heaton, 2003: Last interglacial conditions in southern Europe: Evidence from Ioannina, northwest Greece. Global Planet. Change, 36, $157-$ 170 .

van Kolfschoten, T., P. L. Gibbard, and K. L. Knudsen, Ed., 2003: The Eemian interglacial: A global perspective. Global Planet. Change, 36, 147-217.

Vettoretti, G., and W. R. Peltier, 2004: Sensitivity of glacial inception to orbital and greenhouse gas climate forcing. Quat. Sci. Rev., 23, doi:10.1016/j.quascirev.2003.08.008.

von Storch, H., E. Zorita, J. Jones, Y. Dimitriev, F. GonzlezRouco, and S. Tett, 2004: Reconstructing past climate from noisy data. Science, 306, 679-682.

Wallace, J. M., Y. Yuang, and J. Renwick, 1995: Dynamic contribution to hemispheric mean temperature trends. Science, 270, 780-783.

Widmann, M., 2005: One-dimensional CCA and SVD, and their relationship to regression maps. J. Climate, 18, 2785-2792.

Wolff, J. O., E. Maier-Reimer, and S. Legutke, 1997: The Hamburg Ocean Primitive Equation Model HOPE. Tech. Rep. 13, German Climate Computing Center (DKRZ), Hamburg, Germany, 99 pp.

Zorita, E., and F. González-Rouco, 2002: Are temperaturesensitive proxies adequate for North Atlantic Oscillation reconstructions? Geophys. Res. Lett., 29, 1703, doi:10.1029/ 2002GL015404.

$\longrightarrow, \ldots$, and S. Legutke, 2003: Testing the Mann et al. (1998) approach to paleoclimate reconstructions in the context of a 1000 -yr control simulation with the ECHO-G coupled climate model. J. Climate, 16, 1378-1390.

- H. von Storch, F. J. Gonzales-Rouco, U. Cubasch, J. Luterbacher, S. Legutke, I. Fischer-Bruns, and U. Schlese, 2004: Climate evolution in the last five centuries simulated by an atmosphere-ocean model: Global temperatures, the North Atlantic Oscillation and the late Maunder Minimum. Meteor. Z., 13, 271-289. 